\title{
Effect of Oral Administration of Korean Red Ginseng on Influenza A (H1N1) Virus Infection
}

\author{
Jin Young Kim, Hyoung Jin Kim, and Hong-Jin Kim* \\ College of Pharmacy, Chung-Ang University, Seoul 156-756, Korea
}

\begin{abstract}
Korean red ginseng (RG), which is a ginseng treated by heating and steaming, has biological activity similar to Panax ginseng. The effect of ginseng on influenza infection has not been studied although it is known to have a broad range of biological activities. The aim of the study is to investigate the effect of RG extract on influenza A (H1N1) virus infection. We investigated the inhibitory effect of RG extract on plaque formation by influenza A virus in a cell-based plaque assay, and the effect of orally administered RG on influenza A virus infection in mice. RG extract, which was applied at a non-cytotoxic concentration, inhibited plaque formation by influenza A virus in the cell-based plaque assay. The orally administered RG extract ameliorated body weight loss and significantly increased survival in mice infected with influenza A virus. Our results suggest that RG extract has components that reduce the severity of infection by influenza A virus and could potentially be used as a complement to treatment of influenza A virus infections.
\end{abstract}

Keywords: Panax ginseng, Korean red ginseng, Influenza A virus, Oseltamivir

\section{INTRODUCTION}

Korean ginseng (Panax ginseng) is a novel pharmacological agent that has been used to increase natural energy and physical ability in East Asia for several thousand years $[1,2]$. Recently, it has been proven to have a broad range of biological activities including anti-inflammatory, antioxidant and anti-tumor actions [3]. Red ginseng (RG) is a Panax ginseng that has been treated with heat and steam [4]. It has broad range of biological activities similar to Panax ginseng [5,6]. Its immunomodulatory action is the best-studied effect of ginseng [3,7-10]. However, the anti-viral effect of ginseng, if any, has not yet been examined.

Influenza virus is a common human pathogen that causes serious respiratory illness and has the potential to cause widespread pandemics [11]. Influenza A viruses are the most common types that cause human disease and are subdivided into subtypes based on surface antigens, haemagglutinin and neuraminidase $[12,13]$. The H1N1 influenza virus is a subtype of influenza A virus, and the cause of the Spanish flu of 1918 and the pandemic of 2009. The Spanish flu resulted in 50 million deaths, corresponding to $3 \%$ of the world's population [14]. Recently, the World Health Organization [15] reported that the pandemic of 2009 resulted in 17 thousand deaths, and seasonal flu results in 250 to 500 thousand deaths annually. Therefore, the prevention of influenza infection has become a universal issue.

Four kinds of antiviral agents are available for use against influenza infection. Oseltamivir (Tamiflu ${ }^{\mathbb{B}}$, Roche, Basel, Switzerland), zanamivir (Relenza ${ }^{\circledR}$, Glaxo SmithKline, Vienna, Austria), rimantadine (Flumadine ${ }^{\circledR}$, Forest Pharmaceuticals, New York, NY, USA), and amantadine

\footnotetext{
(c) This is an Open Access article distributed under the terms of the Creative Commons Attribution Non-Commercial License (http://creativecommons.org/licenses/by-nc/3.0/) which permits unrestricted non-commercial use, distribution, and reproduction in any medium, provided the original work is properly cited.
}

Received 26 Nov. 2010, Revised 9 Dec. 2010, Accepted 10 Dec. 2010

*Corresponding author

E-mail: hongjink@cau.ac.kr

Tel: +82-2-820-5613, Fax: +82-2-816-7338 
$\left(\right.$ Symmetrel $^{\circledR}$, Norvatis, Basel, Switerland) are anti-influenza drugs that can reduce the duration of influenza $\mathrm{A}$ virus infection [16]. In addition, administration of vitamin $\mathrm{C}$, vitamin $\mathrm{A}, \mathrm{N}$-acetylcysteine, garlic, and ginseng, are helpful for treating the common cold [11]. Kaneko and Nakanishi [5] have suggested that oral administration of RG is effective in decreasing the incidence of the common cold symptom complex (CCSC), and Predy et al. [17] have suggested that oral administration of a poly-furanosyl-pyranosyl polysaccharide-rich extract of Panax quinquefolium root prevents upper respiratory tract infections. However, there is no clear definition of the effect of ginseng on influenza virus infection because the common cold is caused by a variety of pathogens such as rhinovirus, influenza virus, coronavirus and adenovirus $[13,18]$, and the previous studies were not designed to investigate the effect of ginseng on influenza virus.

In this study, we investigated whether RG extract contains components that inhibit influenza virus A (H1N1) replication in a cell-based plaque assay, and whether orally administered RG extract reduces the severity of influenza A virus infection in mice.

\section{MATERIALS AND METHODS}

\section{Materials}

Four-year-old RG extract was purchased from Geumsan Korean Ginseng Nonghyup (Geumsan, Korea). The extract was dissolved in distilled water (DW) and adjusted to $2.8 \mathrm{mg} / \mathrm{mL}$ (the concentration was based on the residual amount of $\mathrm{RG}$ extract). The preparation was centrifuged at 12,000 $\mathrm{g}$ for $10 \mathrm{~min}$ and filtered through a cellulose membrane $(0.22 \mu \mathrm{m}$ pore size; Whatman, UK). Oseltamivir (Tamiflu) was dissolved in DW and adjusted to $1 \mathrm{mg} / \mathrm{mL}$ [19]. The prepared RG extract and oseltamivir were further diluted with DW in each experiment.

\section{Virus and cell}

To investigate the anti-influenza A (H1N1) virus effect of RG in vitro, we employed Madin-Darby canine kidney (MDCK) cells, which have been frequently used to study influenza virus. The cells were grown in minimal essential medium alpha (Gibco, Grand Island, NY, USA) supplemented with 10\% fetal bovine serum (Hyclone, Logan, UT, USA) and $1 \%$ penicillin-streptomycin (Gibco). Influenza A/PR/8/34 virus (H1N1 subtype) was kindly donated by Professor Man-Seong Park (Hallym University, Chuncheon, Korea). The 50\% lethal dose (LD50) of the influenza A stock was determined as de- scribed [20].

\section{Determination of the non-cytotoxic concentration of RG extract}

To assess the cytotoxicity of RG for MDCK cells, we performed methyl tetrazolium (Sigma, St. Louis, MO, USA) assays [21]. MDCK cells were incubated with various concentrations of RG extract in 96-well tissue culture plates for $48 \mathrm{~h}$ at $37^{\circ} \mathrm{C}$. Color reactions were developed using dimethyl sulfoxide (Sigma) and measured at $540 \mathrm{~nm}$. The highest non-cytotoxic concentration of $\mathrm{RG}$ extract was the highest concentration yielding an optical density similar to that of controls cultured without RG extract.

\section{Cell-based plaque reduction assay}

Plaque reduction assays were performed according to a previous report [22]. Confluent monolayers of MDCK cells in six-well plates were inoculated with 100 plaque forming unit of virus per well for 45 min with rocking. Unattached virus was removed by washing three times with medium and the cells were incubated with overlay medium (DMEM [Gibco] containing 1\% low melting point agarose [Lonza, Rockland, ME, USA], $10 \mu \mathrm{g} / \mathrm{mL}$ trypsin [Invitrogen, Carlsbad, CA, USA] and non-cytotoxic concentrations of RG extracts). Three days later the monolayers were fixed with $4 \%$ formalin, and the agarose removed. The monolayers were stained with $1 \%$ crystal violet and $20 \%$ methanol in phosphate buffered saline, and plaques were counted.

\section{Animals}

Five-to-seven-week-old female C57BL/6 mice were purchased from Orient Bio (Seongnam, Korea) and acclimatized for 1 week. All animal experiments were performed in accordance with the National Research Council's Guide for the Care and Use of Laboratory Animals and with the Guidelines for Animal Experiments of Chung-Ang University, and were approved by the University Committee for Animal Experiments.

\section{Effect of oral administration of RG extract on mice infected with influenza $A$ virus}

To investigate the effect of RG extract on influenza infection, body weights and survival rates of mice were monitored for 14 and 15 days (Fig. 1). Mice were divided into three groups (DW-, oseltamivir-, and RG extract-), each consisting of four to six mice. Prior to virus challenge, two of the groups received orally DW ( $200 \mu \mathrm{L} /$ day $)$ and one $R G$ extract (10 mg/kg/day) for 14 days (Fig. 1). The 
A Body weight change

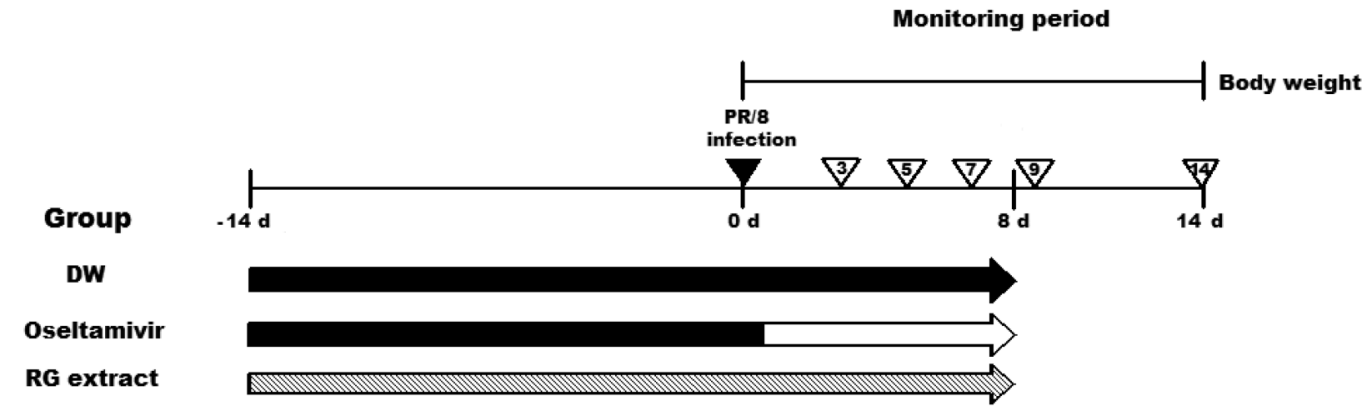

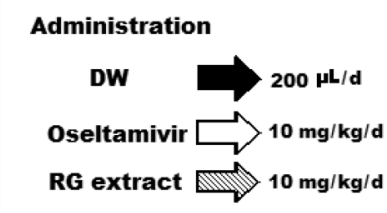

B

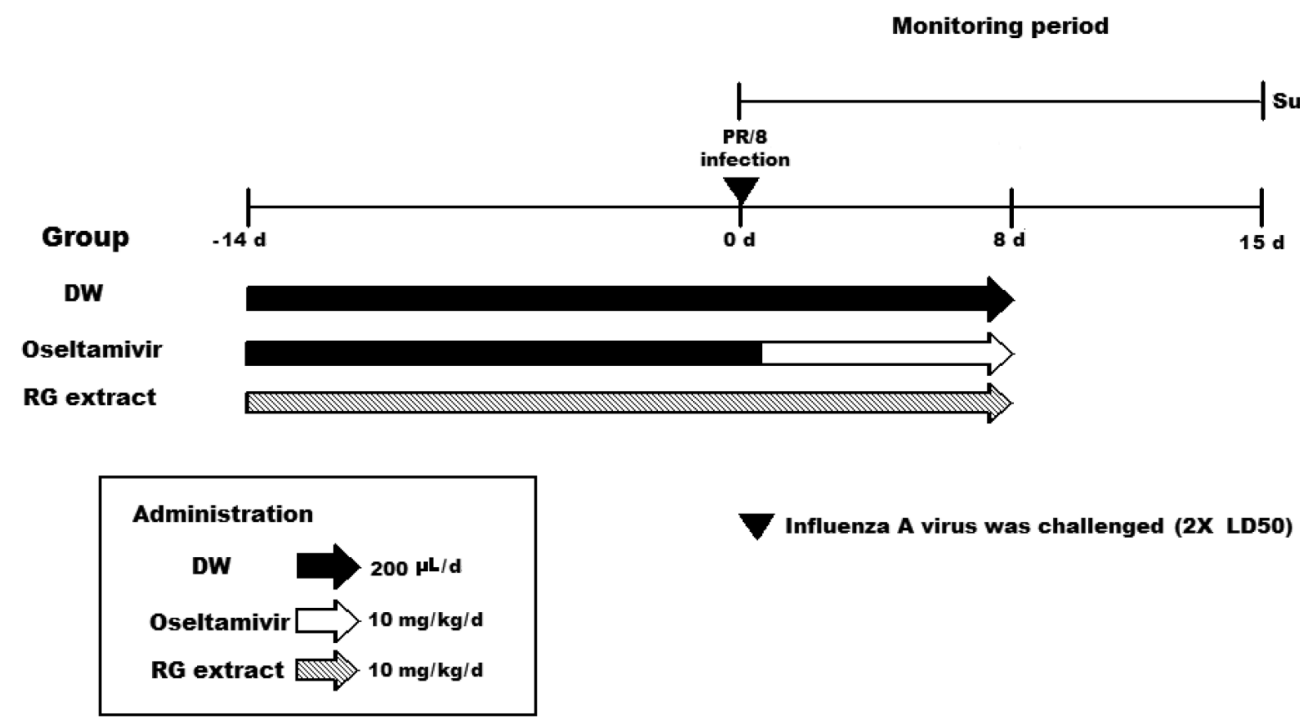

Fig. 1. Overview of the experimental schedules. The schedules for measuring body weight and survival rate are shown in (A) and (B), respectively. Distilled water (DW) and red ginseng (RG) extract were orally administered to mice for 14 days prior to influenza $A$ virus (A/Puerto Rico/8/34, PR/8) challenge, and then DW, oseltamivir and RG extract were orally administered for a further 8 days. The mice used to investigate body weight change and survival were instilled intranasally with $0.2 X$ and 2X LD50 of influenza A virus and monitored for 14 and 15 days, respectively. Whole lungs for measuring viral titer were collected on days $3,5,7,9$, and 14 after virus challenge (A).

mice were then anesthetized intraperitoneally (i.p.) with zoletil $50(50 \mathrm{mg} / \mathrm{kg}$; Virbac Animal Health, Fort Worth, TX, USA), and exposed to $50 \mu \mathrm{L}$ of virus by intranasal instillation (i.n.) $[23,24]$. To monitor changes of body weight and survival, the mice were challenged with $0.2 \mathrm{X}$ and 2X LD50 of virus, respectively (Fig. 1A, B), following which the three groups were given DW, oseltamivir or RG extract for 8 days as shown in Fig. 1, and body weights and survival rates were monitored for 14 and 15 days, respectively, after virus challenge (Fig. 1A, B).
The body weight of each mouse one day before virus challenge was set at $100 \%$.

\section{Analysis of viral titers in the lung}

Whole lungs were collected on days 3, 5, 7, 9, and 14 post virus challenge (Fig. 1A), homogenized with a Dounce homogenizer and centrifuged at $12,000 \mathrm{~g}$ for 10 min. The supernatants were frozen at $-70^{\circ} \mathrm{C}$ for subsequent virus titration. The virus titration was performed according to previous reports $[22,25]$. 


\section{Statistical analysis}

The statistical significance of differences between groups was determined using a two-tailed Student's $t$-test. A $p$ value less than 0.01 was considered statistically significant.

\section{RESULTS}

\section{Inhibitory effect of RG extract on plaque formation by influenza A virus in MDCK cells}

Concentrations of RG extract below $140 \mu \mathrm{g} / \mathrm{mL}$ were found to be non-cytotoxic to MDCK cells (data not shown). As shown in Fig. 2, RG extract dose-dependently inhibited plaque formation by influenza A virus. Since the $R G$ extracts were applied after virus adsorption this result indicates that the RG extract contains components inhibiting the replication of influenza A virus.

\section{Effect of oral administration of RG extract on mice infected with influenza $A$ virus}

RG extract was administered orally for 14 days prior to virus challenge and for a further 8 days post challenge. To investigate body weight change and survival rate following influenza $\mathrm{A}$ virus infection, $0.2 \mathrm{X}$ and $2 \mathrm{X}$ $\mathrm{LD}_{50}$ of virus, respectively, were given (Fig. 1A, B). As shown in Fig. 3A, the body weights of the oseltamiviradministered group (positive control) did not change for 14 days. The body weights of both the DW and RG groups fell significantly by the eighth day post infection but those of the RG groups recovered considerably. This result

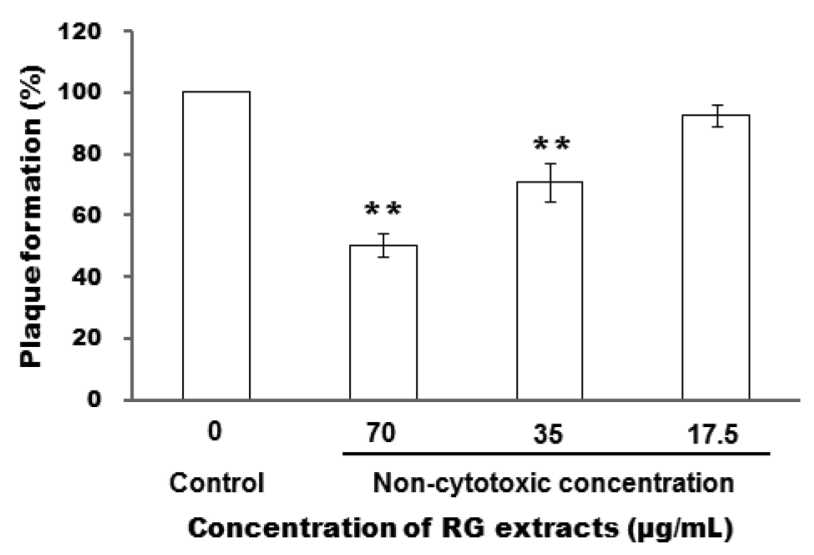

Fig. 2. Inhibitory effect of red ginseng (RG) extract on plaque formation. Confluent monolayers of Madin-Darby canine kidney cells in six-well plates were infected with influenza A virus and cultured with overlay medium containing non-cytotoxic concentrations $(0,70$, 35 , and $17.5 \mu \mathrm{g} / \mathrm{mL}$ ) of $R G$ extract as described in Materials and Methods. Control plaque numbers were set at $100 \%$. The values are means $\pm S D$ of three independent experiments. ${ }^{* *} p<0.01$ compared to control plaque number.

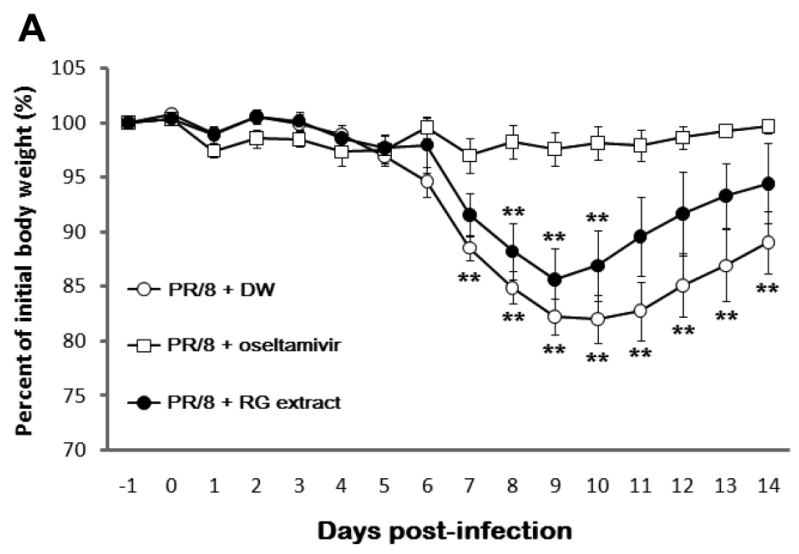

B

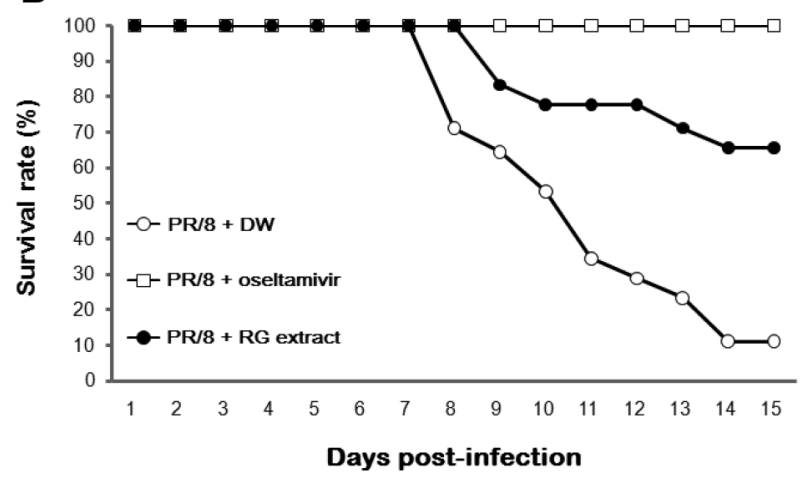

Fig. 3. Effect of oral administration of distilled water (DW), oseltamivir and red ginseng (RG) extract on influenza $A$ virus infection of mice. Three mice groups were administered orally with DW or RG extract for 14 days prior to virus challenge (see Fig. 1). After virus challenge, administration was continued for 8 days as described in Fig. 1. Daily monitored body weights and survival are presented in (A) and (B), respectively. Body weight one day before virus challenge was set at $100 \%$. The values in $(A)$ are means \pm SEM of twelve individual mice from three separate experiments $(n=12)$. The values in (B) are percentages from three separate experiments $(n=17)$. ${ }^{* *} p<0.01$ compared to the body weights of the oseltamivir-administered group. PR/8, A/Puerto Rico/8/34.

indicates that oral administration of RG extract significantly reduces the severity of influenza A virus infection.

As shown in Fig. 3B, survival of the RG group was $66 \%$ at fifteen days post infection, while that of the DW group was $10 \%$. This suggests that the RG components of RG absorbed through the intestinal tract not only reduce the severity of influenza A virus infection in mice but also increase survival.

\section{Effect of oral administration of RG extract on influ- enza $A$ virus replication in vivo}

The whole lungs of three mice group were collected on days $3,5,7,9$, and 14 post virus challenge, and lung virus titers were measured (Fig. 1A). It is known that the administration of neuraminidase inhibitors such as oseltamivir does not reduce lung virus titers very efficiently 


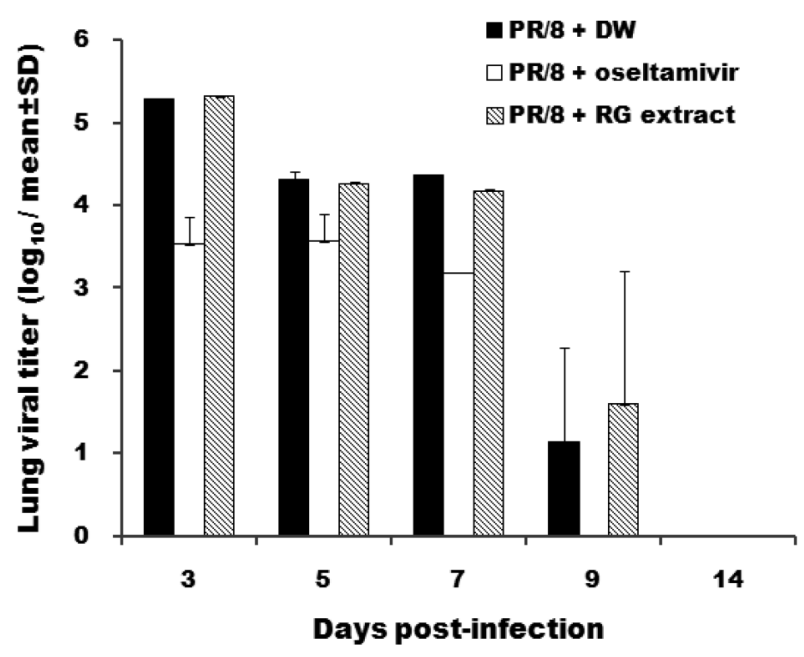

Fig. 4. Lung virus titers in influenza A-infected mice given distilled water (DW), oseltamivir or red ginseng (RG) extract. Whole lungs of each group were collected on days $3,5,7,9$, and 14 post-virus challenge. Values are mean $\pm \mathrm{SD}$ of three individual mice $(n=3)$. PR/8, A/ Puerto Rico/8/34.

in lethal influenza virus infections [26,27], and this was also true in the present case. As shown in Fig. 4, the viral titer in the oseltamivir group was about tenfold lower than in the DW group in which all the mice perished by day 9 after challenge. The virus titers of the RG group were the same as those of the DW group although their symptoms were substantially less (Figs. 3 and 4). Thus we have shown that the $\mathrm{RG}$ extract, absorbed through the intestinal tract, reduces the severity of infection but does not inhibit influenza virus replication in the mouse lung.

\section{DISCUSSION}

Seasonal influenza infection is accompanied by symptoms such as coryza, cough, headache, prostration, and malaise that persist for 7 to 10 days in humans [28]. In the mouse model, however, the major symptom parameters are weight loss and virus in the lungs [29]. We showed above that RG extract contains components inhibiting influenza A virus replication in vitro, and that orally administered RG extract not only ameliorates weight loss but also decreases death in influenza virusinfected mice.

It has been proposed that excessive or dysregulated lung inflammation is responsible for influenza-induced mortality [30,31]. Cilloniz et al. [30] have showed that virus type H5N1 VN/1203 is more lethal than the H1N1 1918 pandemic virus in mice even though there was no difference in lung virus titers; however the greater lethality of $\mathrm{H} 5 \mathrm{~N} 1 \mathrm{VN} / 1203$ was associated with an earlier and stronger inflammatory response and a down-regulated anti-inflammatory response. Therefore, it seems that the inflammatory response has an important effect on the symptoms and lethality of influenza virus infection.

Yeung et al. [32] have suggested that injection of the total saponins extracted from Panax ginseng has no significant effect on the generation of cytotoxic $\mathrm{T}$ cell activity, induction of natural killer cell activity and humoral antibody production in mice infected with virus. Biondo et al. [33] have shown that oral administration of a polyfuranosyl-pyranosyl polysaccharide-rich extract of North American ginseng (CVT-E002) can delay the production of pro-inflammatory cytokines such interferon- $\gamma$, tumor necrosis factor- $\alpha$ and intereukin- $1 \beta$. Consequently, these previous reports indicate that ginseng extract may reduce inflammatory responses, rather than simply up-regulating the immune system to eliminate infected virus. Also in the present study, the lung virus titer in the RG extract-administered group was not different from that of the DW-administered group whereas the severity of infection was significantly lower (Figs. 3 and 4). Therefore, we assume that the orally administered RG extract acts indirectly to decrease symptoms by counteracting inflammatory responses rather than by directly inhibiting virus replication.

Mutations are frequent in RNA viruses including influenza, because of the lack of proof reading mechanisms [34]. This characteristic offers them the opportunity to avoid the immune system and antiviral drugs $[35,36]$. In 2009, the Center for Disease Control and Prevention [37] reported that $100 \%$ of seasonal influenza A (H3N2) and $99.6 \%$ of seasonal influenza A (H1N1) were resistant to amantadine and oseltamivir, respectively. In addition, the emergence of the oseltamivir-resistant 2009 pandemic influenza A (H1N1) virus was reported in 2009 [37]. Therefore, the widespread and sustained use of these antiviral agents raises concerns over the emergence of influenza viruses resistant to anti-influenza agents. These agents directly target components of the influenza virus such as neuraminidase and M2 protein $[38,39]$. Thus the rapid evolution of influenza virus will continually call for new treatment strategies.

In this study we have presented evidence that oral administration of RG extract is effective in reducing the severity of influenza A virus infection. Our data suggest that orally administered RG acts indirectly to reduce the severity of infection. We propose that RG extract may offer a new strategy for treating influenza virus infection. A previous report suggested that the incidence of 
CCSC in an RG-administered cohort was three times lower than in a cohort not taking RG [5]. However, just $10 \%$ to $15 \%$ of common colds are caused by influenza virus [11]. Therefore, the effect of RG extract in reducing the incidence of CCSC implies that RG extract is also effective against other viruses such as rhinoviruses and coronaviruses, which are also major causes of the common cold. We anticipate that further studies will lead to an understanding of how ginseng extract acts on influenza virus infections.

\section{ACKNOWLEDGEMENTS}

We thank Professor Man-Seong Park (Hallym University, Chuncheon, Korea) and Professor Baik-Lin Sung (Younsei University, Seoul, Korea) for help with the experiments. This research was supported by a grant from Geumsan.

\section{REFERENCES}

1. Coleman CI, Hebert JH, Reddy P. The effects of Panax ginseng on quality of life. J Clin Pharm Ther 2003;28:5-15.

2. Kim MH, Hong HD, Kim YC, Rhee YK, Kim KT, Rho J. Ginsenoside changes in red ginseng manufactured by acid impregnation treatment. J Ginseng Res 2010;34:93-97.

3. Block KI, Mead MN. Immune system effects of echinacea, ginseng, and astragalus: a review. Integr Cancer Ther 2003;2:247-267.

4. Keum YS, Park KK, Lee JM, Chun KS, Park JH, Lee SK, Kwon H, Surh YJ. Antioxidant and anti-tumor promoting activities of the methanol extract of heat-processed ginseng. Cancer Lett 2000;150:41-48.

5. Kaneko H, Nakanishi K. Proof of the mysterious efficacy of ginseng: basic and clinical trials: clinical effects of medical ginseng, korean red ginseng: specifically, its anti-stress action for prevention of disease. J Pharmacol Sci 2004;95:158162.

6. Sung H, Jung YS, Cho YK. Beneficial effects of a combination of Korean red ginseng and highly active antiretroviral therapy in human immunodeficiency virus type 1-infected patients. Clin Vaccine Immunol 2009;16:1127-1131.

7. Hu S, Concha C, Johannisson A, Meglia G, Waller KP. Effect of subcutaneous injection of ginseng on cows with subclinical Staphylococcus aureus mastitis. J Vet Med B Infect Dis Vet Public Health 2001;48:519-528.

8. Lee YS, Chung IS, Lee IR, Kim KH, Hong WS, Yun YS. Activation of multiple effector pathways of immune system by the antineoplastic immunostimulator acidic polysaccharide ginsan isolated from Panax ginseng. Anticancer Res
1997; 17:323-331.

9. Luo YM, Cheng XJ, Yuan WX. Effects of ginseng root saponins and ginsenoside Rb1 on immunity in cold water swim stress mice and rats. Zhongguo Yao Li Xue Bao 1993;14: 401-404.

10. Sumiyoshi M, Sakanaka M, Kimura Y. Effects of red ginseng extract on allergic reactions to food in Balb/c mice. $\mathrm{J}$ Ethnopharmacol 2010;132:206-212.

11. Roxas M, Jurenka J. Colds and influenza: a review of diagnosis and conventional, botanical, and nutritional considerations. Altern Med Rev 2007;12:25-48.

12. Klenk E, Faillard H, Lempfrid H. Enzymatic effect of the influenza virus. Hoppe Seylers Z Physiol Chem 1955;301:235246.

13. Cox RJ, Brokstad KA, Ogra P. Influenza virus: immunity and vaccination strategies. Comparison of the immune response to inactivated and live, attenuated influenza vaccines. Scand J Immunol 2004;59:1-15.

14. Johnson NP, Mueller J. Updating the accounts: global mortality of the 1918-1920 "Spanish" influenza pandemic. Bull Hist Med 2002;76:105-115.

15. World Health Organization. Situation updates: pandemic (H1N1) 2009. Available from: http://www.who.int/csr/disease/swineflu/updates/en/.

16. Bearman GM, Shankaran S, Elam K. Treatment of severe cases of pandemic (H1N1) 2009 influenza: review of antivirals and adjuvant therapy. Recent Pat Antiinfect Drug Discov 2010;5:152-156.

17. Predy GN, Goel V, Lovlin R, Donner A, Stitt L, Basu TK. Efficacy of an extract of North American ginseng containing poly-furanosyl-pyranosyl-saccharides for preventing upper respiratory tract infections: a randomized controlled trial. CMAJ 2005;173:1043-1048.

18. Varkey JB, Varkey B. Viral infections in patients with chronic obstructive pulmonary disease. Curr Opin Pulm Med 2008; 14:89-94.

19. Morimoto K, Nakakariya M, Shirasaka Y, Kakinuma C, Fujita T, Tamai I, Ogihara T. Oseltamivir (Tamiflu) efflux transport at the blood-brain barrier via P-glycoprotein. Drug Metab Dispos 2008;36:6-9.

20. Reed LJ, Muench H. A simple method of estimating fifty percent endpoints. Am J Hyg 1938;27:493-497.

21. Fotakis G, Timbrell JA. In vitro cytotoxicity assays: comparison of LDH, neutral red, MTT and protein assay in hepatoma cell lines following exposure to cadmium chloride. Toxicol Lett 2006;160:171-177.

22. Hayden FG, Cote KM, Douglas RG Jr. Plaque inhibition assay for drug susceptibility testing of influenza viruses. Antimicrob Agents Chemother 1980;17:865-870.

23. Saad WA, de Arruda Camargo LA, Simoes S, Saad WA, 
Guarda RS, Guarda IF. Moxonidine and rilmenidine injected into the medial septal area reduces the salivation induced by pilocarpine. Auton Neurosci 2004;112:31-36.

24. Yen HL, Monto AS, Webster RG, Govorkova EA. Virulence may determine the necessary duration and dosage of oseltamivir treatment for highly pathogenic A/Vietnam/1203/04 influenza virus in mice. J Infect Dis 2005;192:665-672.

25. Sidwell RW, Huffman JH, Call EW, Alaghamandan H, Cook PD, Robins RK. Effect of selenazofurin on influenza A and B virus infections of mice. Antiviral Res 1986;6:343-353.

26. Sidwell RW, Huffman JH, Barnard DL, Bailey KW, Wong $\mathrm{MH}$, Morrison A, Syndergaard T, Kim CU. Inhibition of influenza virus infections in mice by GS4104, an orally effective influenza virus neuraminidase inhibitor. Antiviral Res 1998;37:107-120.

27. Kiso M, Kubo S, Ozawa M, Le QM, Nidom CA, Yamashita M, Kawaoka Y. Efficacy of the new neuraminidase inhibitor CS-8958 against H5N1 influenza viruses. PLoS Pathog 2010;6:e1000786.

28. Taubenberger JK, Morens DM. The pathology of influenza virus infections. Annu Rev Pathol 2008;3:499-522.

29. Barnard DL. Animal models for the study of influenza pathogenesis and therapy. Antiviral Res 2009;82:A110-A122.

30. Cilloniz C, Pantin-Jackwood MJ, Ni C, Goodman AG, Peng X, Proll SC, Carter VS, Rosenzweig ER, Szretter KJ, Katz $\mathrm{JM}$, et al. Lethal dissemination of H5N1 influenza virus is associated with dysregulation of inflammation and lipoxin signaling in a mouse model of infection. J Virol 2010;84: 7613-7624.

31. Kobasa D, Jones SM, Shinya K, Kash JC, Copps J, Ebihara
H, Hatta Y, Kim JH, Halfmann P, Hatta M, et al. Aberrant innate immune response in lethal infection of macaques with the 1918 influenza virus. Nature 2007;445:319-323.

32. Yeung HW, Cheung K, Leung KN. Immunopharmacology of Chinese medicine 1, ginseng induced immunosuppression in virus-infected mice. Am J Chin Med 1982;10:4454.

33. Biondo PD, Goruk S, Ruth MR, O'Connell E, Field CJ. Effect of CVT-E002 (COLD-fX) versus a ginsenoside extract on systemic and gut-associated immune function. Int Immunopharmacol 2008;8:1134-1142.

34. Steinhauer DA, Domingo E, Holland JJ. Lack of evidence for proofreading mechanisms associated with an RNA virus polymerase. Gene 1992;122:281-288.

35. Moscona A. Global transmission of oseltamivir-resistant influenza. N Engl J Med 2009;360:953-956.

36. Hatakeyama S. Drug-resistant influenza viruses: an overview. Nippon Rinsho 2010;68:1671-1678.

37. Centers for Disease Control and Prevention. 2008-2009 influenza season week 35 ending September 5, 2009. Available from: http://www.cdc.gov/flu/weekly/pdf/External_ F0935.pdf.

38. Intharathep P, Laohpongspaisan C, Rungrotmongkol T, Loisruangsin A, Malaisree M, Decha P, Aruksakunwong O, Chuenpennit K, Kaiyawet N, Sompornpisut P, et al. How amantadine and rimantadine inhibit proton transport in the M2 protein channel. J Mol Graph Model 2008;27:342348.

39. Moscona A. Neuraminidase inhibitors for influenza. N Engl J Med 2005;353:1363-1373. 